\title{
Live load model for highway bridges *
}

\author{
Andrzej S. Nowak \\ Department of Civil and Environmental Engineering, University of Michigan, Ann Arbor, MI 48109, USA
}

\begin{abstract}
Load models are developed for highway bridges. The models are based on the available statistical data on dead load, truck loads and dynamic loads. The paper deals mostly with the static live load. The model is derived from truck surveys, weigh-in-motion measurements and other observations. Simple span moments, shears and negative moments are calculated for various spans. Extreme 75 year loads are determined by extrapolation. The important parameters also include girder distribution factors and multiple presence (more than one truck on the bridge). Multiple presence is considered in lane and side-by-side with various degrees of correlation between truck weights. The maximum load is calculated by simulations. The developed live load model served as a basis for the development of new design provisions in the United States (LRFD AASHTO) and Canada (Ontario Highway Bridge Design Code).
\end{abstract}

Key words: highway bridges; live load; multiple presence; truck load.

\section{Introduction}

The major load components of highway bridges are dead load, live load (static and dynamic), environmental loads (temperature, wind, earthquake) and other loads (collision, emergency braking). Load components are random variables. Their variation is described by the cumulative distribution function (CDF), and/or parameters such as the mean value, bias factor (mean-to-nominal ratio) and coefficient of variation. The relationship among various load parameters is described in terms of the coefficients of correlation.

The basic load combination for highway bridges is a simultaneous occurrence of dead load, live load and dynamic load. Therefore, these three load components are considered in the present study. It is assumed that the economic life time for newly designed bridges is 75 years. The extreme values of load are extrapolated from the available data base. Nominal (design) values of load components are calculated according to AASHTO [1].

Dead load is the gravity load due to the self weight of the structural and non structural elements permanently connected to the bridge. Because of different degrees of variation, it is convenient to consider three components of dead load: weight of factory made elements (steel, precast concrete members), weight of cast-in-place concrete members, and weight of the

\footnotetext{
* Discussion is open until June 1994 (please submit your discussion paper to the Editor, Ross B. Corotis).
} 
TABLE 1

Statistical parameters of dead load

\begin{tabular}{lcl}
\hline Component & Bias & Coefficient of variation \\
\hline Factory-made members & 1.03 & 0.08 \\
Cast-in-place members & 1.05 & 0.10 \\
Asphalt & $90 \mathrm{~mm} *$ & 0.25 \\
\hline
\end{tabular}

* mean thickness

wearing surface (asphalt). All components of dead load are treated as normal random variables. The statistical parameters were derived in conjunction with the development of the OHBDC [2-4] and they are listed in Table 1. The bias factors are taken as used in the previous bridge code calibration work, however, the coefficients of variation are increased to include human error as recommended by Ellingwood, Galambos, MacGregor and Cornell [5].

Live load covers a range of forces produced by vehicles moving on the bridge. The effect of live load depends on many parameters including the span length, truck weight, axle loads, axle configuration, position of the vehicle on the bridge (transverse and longitudinal), number of vehicles on the bridge (multiple presence), girder spacing, and stiffness of structural members (slab and girders). The effect of these parameters is considered separately.

The dynamic load model was developed by Hwang and Nowak [6]. It is a function of three major parameters: road surface roughness, bridge dynamics (frequency of vibration) and vehicle dynamics (suspension system). It was observed that dynamic deflection is almost constant and it does not depend on truck weight. Therefore, the dynamic load, as a fraction of live load, decreases for heavier trucks. For the maximum 75 year values, the corresponding dynamic load does not exceed 0.15 of live load for a single truck and 0.10 of live load for two trucks side-by-side. The coefficient of variation of dynamics load is about 0.80 . The results of the simulations indicate that DLF (dynamic load factor) values are almost equally dependent on road surface roughness, bridge dynamics and vehicle dynamics. The actual contribution of these three parameters varies from site to site and it is very difficult to predict. Therefore, it is recommended to specify DLF as a constant percentage of live load.

The development of live load model is essential for a rational bridge design and/or evaluation code. Ghosn and Moses [7] proposed statistical parameters for truck load, including weight, axle configuration, dynamic load and future growth. Their values were based on the weigh-in-motion data [8]. The live load model for the first two editions of OHBDC [2] was developed by Nowak and Lind [3]. The model was revised by Nowak and Hong [9]. The present study is a continuation and extension of the previous work.

\section{Data base}

The available weigh-in-motion data was analyzed by Liu and Imbsen as part of NCHRP Project 12-28(11) (unpublished). However, it was found that a large portion of the data collected in mid 1980's was not reliable, with errors estimated at $30-40 \%$. Therefore, in this study, the data base consists of the results of truck survey performed by the Ontario Ministry of Transportation [10]. The study covered 9,250 selected trucks (only trucks which appeared to be heavily loaded were measured and included in the data base). 


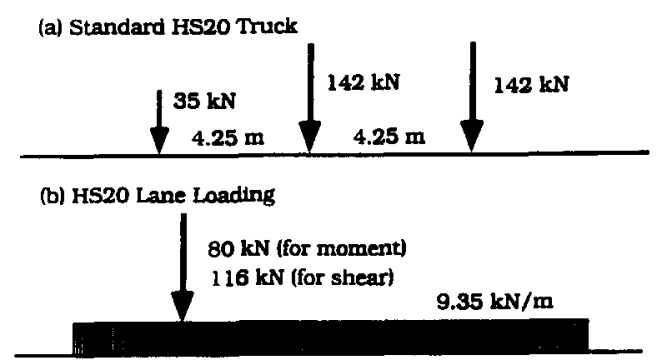

Fig. 1. HS20 Loading, AASHTO [1].

The uncertainties involved in the analysis are due to limitations and biases in the survey. The available data base is small compared to the actual number of heavy vehicles in a 75 year life time. It is also reasonable to expect that some extremely heavy trucks purposefully avoided the weighing stations. A considerable degree of uncertainty is caused by unpredictability of the future trends with regard to configuration of axles and weights.

The data base includes truck configuration (number of axles and axle spacing) and weights (axle loads and gross vehicle weight). For each truck in the survey, bending moments and shear forces are calculated for a wide range of spans. Simple spans and continuous two equal spans are considered. The moments and shears are calculated in terms of the standard HS20 truck or lane loading, whichever governs [1], as shown in Fig. 1. The CDF's are plotted on normal probability paper in Fig. 2, 3 and 4, for simple span moments, shears and negative moments (continuous spans), respectively, for spans from 9 to $60 \mathrm{~m}$. For a random variable $X$ (moment or shear), and CDF, $F_{X}(x)$, the vertical scale, $z$, in Fig. 2 to 4 , is

$z=\Phi^{-1}[F(x)]$

where $\Phi^{-1}=$ inverse of the standard normal distribution function.

\section{Maximum truck moments and shears}

The maximum moments and shears for various time periods are determined by extrapolation. The extrapolated distributions are also shown in Fig. 2 to 4 . Let $N$ be the total number of trucks in time period $T$. It is assumed that the surveyed trucks represent about two week traffic. Therefore, in $T=75$ years, the number of trucks, $N$, will be about 2,000 times larger than in the survey. This will result in $N=20$ million trucks. The probability level corresponding to $N$ is $5 \cdot 10^{-8}$, which corresponds to $z=5.33$. The number of trucks, $N$, probabilities, $1 / N$, and inverse normal distribution values, $z$, corresponding to various time periods $T$ from 1 day to 75 years, are shown in Table 2.

The mean maximum moments and shears corresponding to various periods of time can be determined from CDF's. The results for time periods from 1 day to 75 years are presented in Fig. 5, 6 and 7, for simple span moments, shears and negative moments, respectively. For comparison, the means are also given for an average truck. The moments and shears are divided by the corresponding HS20 design values [1].

The coefficients of variation for the maximum truck moments and shears can be calculated by transformation of $\mathrm{CDF}$. Each function can be raised to a certain power, so that the 


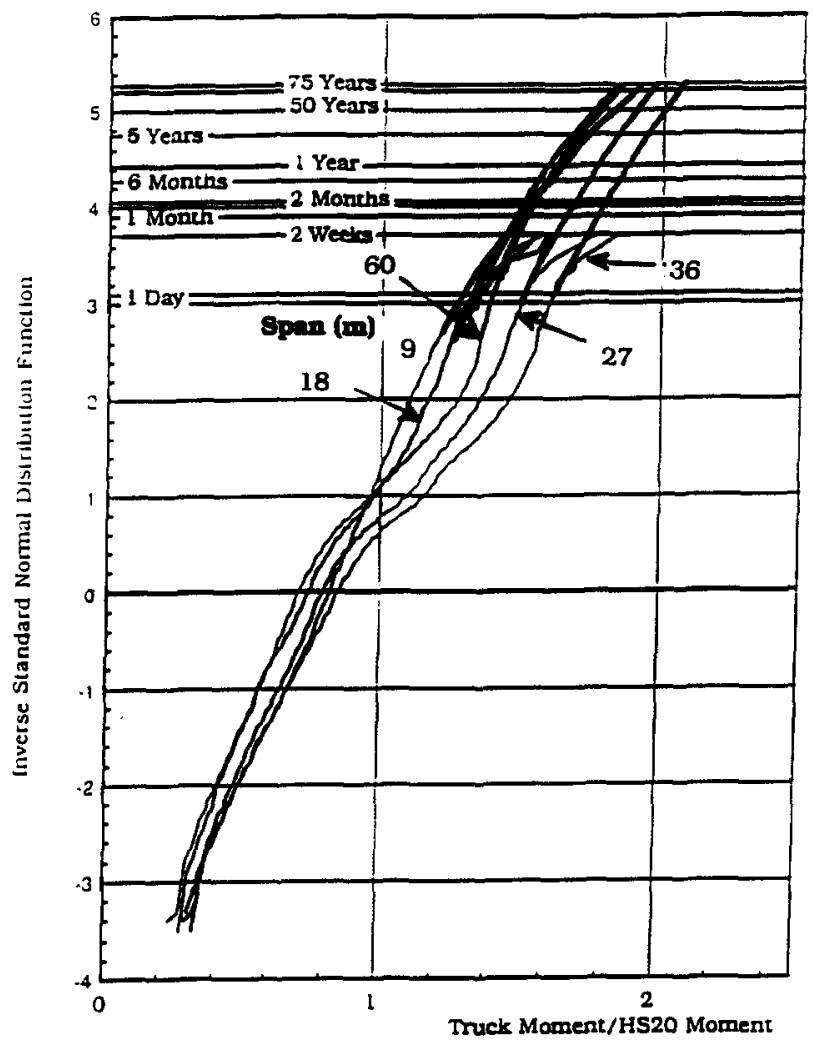

Fig. 2. CDF of moments for simple spans.

calculated earlier mean maximum moment (or shear) becomes the mean value after the transformation. The slope of the transformed CDF determines the coefficient of variation. The results are plotted in Fig. 8 and 9 for moments and shears, respectively.

\section{One lane moments and shears}

The maximum one lane moment or shear is caused either by a single truck or two (or more) trucks following behind each other. For a multiple truck occurrence, the important parameters are the headway distance and degree of correlation between truck weights. The maximum one lane effect (moment or shear) is derived as the largest of the following two cases:

(a) One truck effect, equal to maximum 75 year moment (or shear) with the parameters given in Fig. 5 to 7 for the mean and in Fig. 8 and 9 for the coefficient of variation;

(b) Two trucks, each with the weight smaller than that of a single truck in (a). Various headway distances are considered, from 5 to $30 \mathrm{~m}$. Headway distance is measured from the rear axle of one vehicle to the front axle of the following vehicle, therefore $5 \mathrm{~m}$ means bumper to bumper traffic. Three degrees of correlation between truck weight are considered: $\rho=0$ (no correlation), $\rho=0.5$ (partial) and $\rho=1$ (full correlation), where $\rho$ is the coefficient of correlation. 


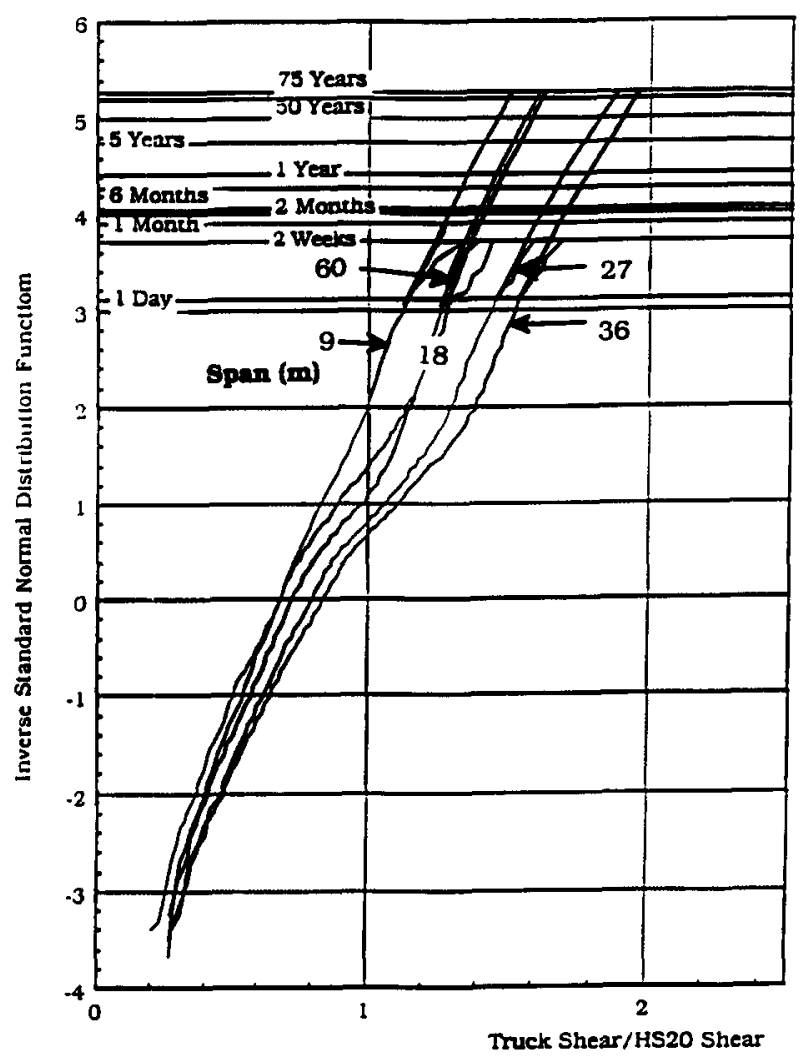

Fig. 3. CDF of shears.

Observations indicate that, on average, about every 50th truck is followed by another truck with the headway distance less than $30 \mathrm{~m}$ [11]. It also assumed that about every 150th truck is followed by a partially correlated truck, and about every 500th truck is followed by a fully correlated truck. The parameters of the two trucks in lane, including $N$ (the considered truck is a maximum of $\mathrm{N}$ trucks), corresponding $z=-\Phi^{-1}(1 / N)$, and $T$ (the considered truck is the maximum for time period $T$ ) are given in Table 3 .

The maximum values of moments and shears are calculated by simulations. The parameters considered include truck configuration, weight, headway distance and frequency of occurrence. The mean 75 year values are shown in Fig. 10, 11 and 12 for simple span moments, shears and negative moments, respectively.

\section{Girder distribution factors}

The analysis of two lane loading involves the distribution of truck load to girders. The structural analysis is carried out using the finite element method. The model is based on a linear behavior of girders and slab. The calculations are performed for spans ranging from 9 to $60 \mathrm{~m}$. Five cases of girder spacing are considered: 1.2, 1.8, 2.4, 3.0 and $3.6 \mathrm{~m}$. For each case of span and girder spacing, girder distribution factors are calculated for various truck positions, by 


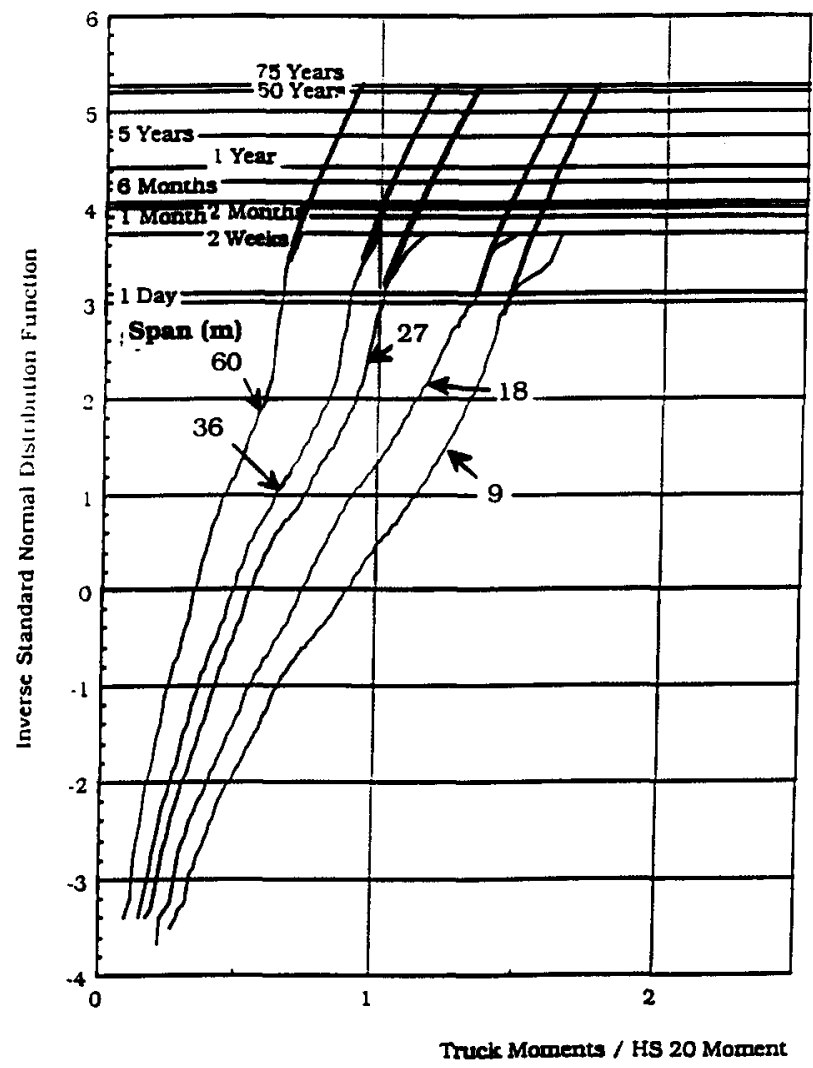

Fig. 4. CDF of negative moments for continuous spans.

moving the truck transversely by $0.3 \mathrm{~m}$ at a time. The resulting truck "influence lines" are used for calculation of the joint effect of two trucks in adjacent lanes, by superposition.

The resulting girder distribution factors (GDF) are compared with the AASHTO (1989) values and those recommended by Zokaie et al. [12].

\section{TABLE 2}

Number of trucks, vs. time period and probability

\begin{tabular}{|c|c|c|c|}
\hline $\begin{array}{l}\text { Time period } \\
T\end{array}$ & $\begin{array}{l}\text { Number of trucks } \\
N\end{array}$ & $\begin{array}{l}\text { Probability } \\
1 / N\end{array}$ & $\begin{array}{l}\text { Inverse normal } \\
z\end{array}$ \\
\hline 75 years & $20,000,000$ & $5 \cdot 10^{-8}$ & 5.33 \\
\hline 50 years & $15,000,000$ & $7 \cdot 10^{-8}$ & 5.27 \\
\hline 5 years & $1,500,000$ & $7 \cdot 10^{-7}$ & 4.83 \\
\hline 1 year & 300,000 & $3 \cdot 10^{-6}$ & 4.50 \\
\hline 6 months & 150,000 & $7 \cdot 10^{-6}$ & 4.36 \\
\hline 2 months & 50,000 & $2 \cdot 10^{-5}$ & 4.11 \\
\hline 1 month & 30,000 & $3 \cdot 10^{-5}$ & 3.99 \\
\hline 2 weeks & 10,000 & $1 \cdot 10^{-4}$ & 3.71 \\
\hline 1 day & 1,000 & $1 \cdot 10^{-3}$ & 3.09 \\
\hline
\end{tabular}




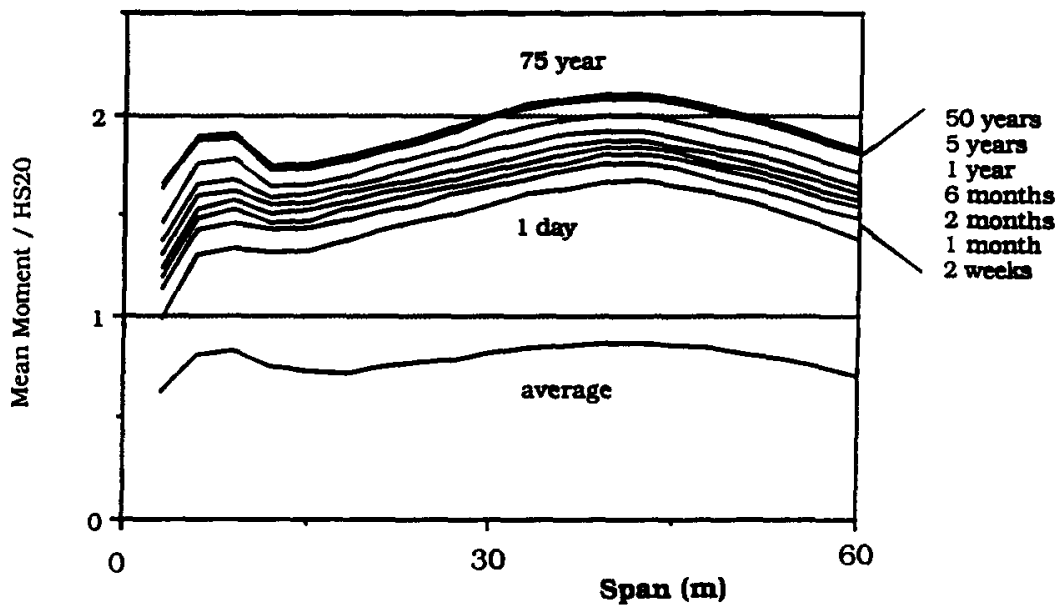

Fig. 5. Mean maximum moments for simple spans.

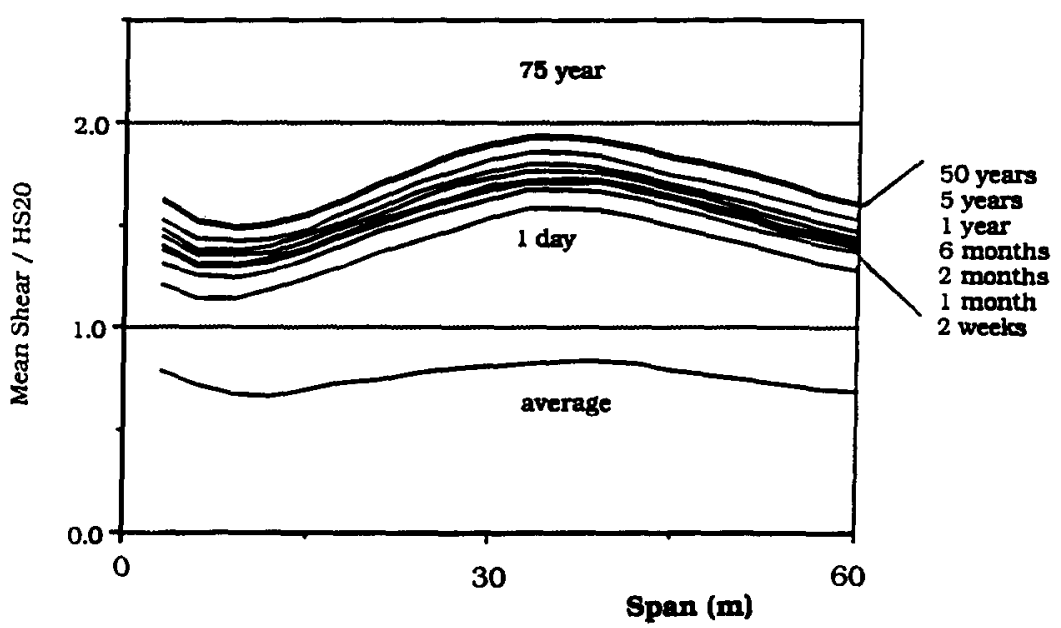

Fig. 6. Mean maximum shears.

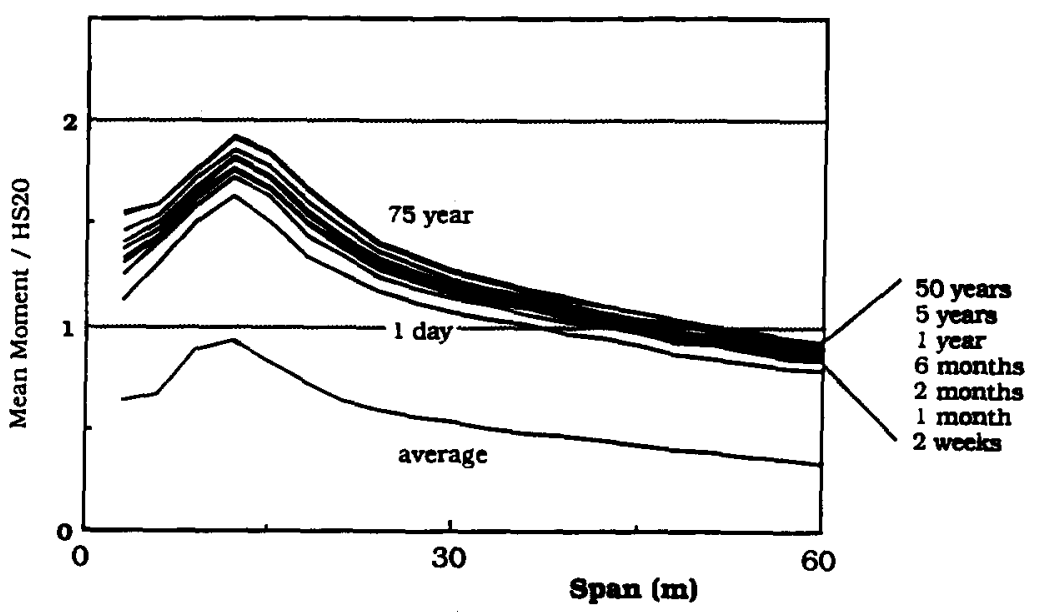

Fig. 7. Mean maximum negative moments for continuous spans. 


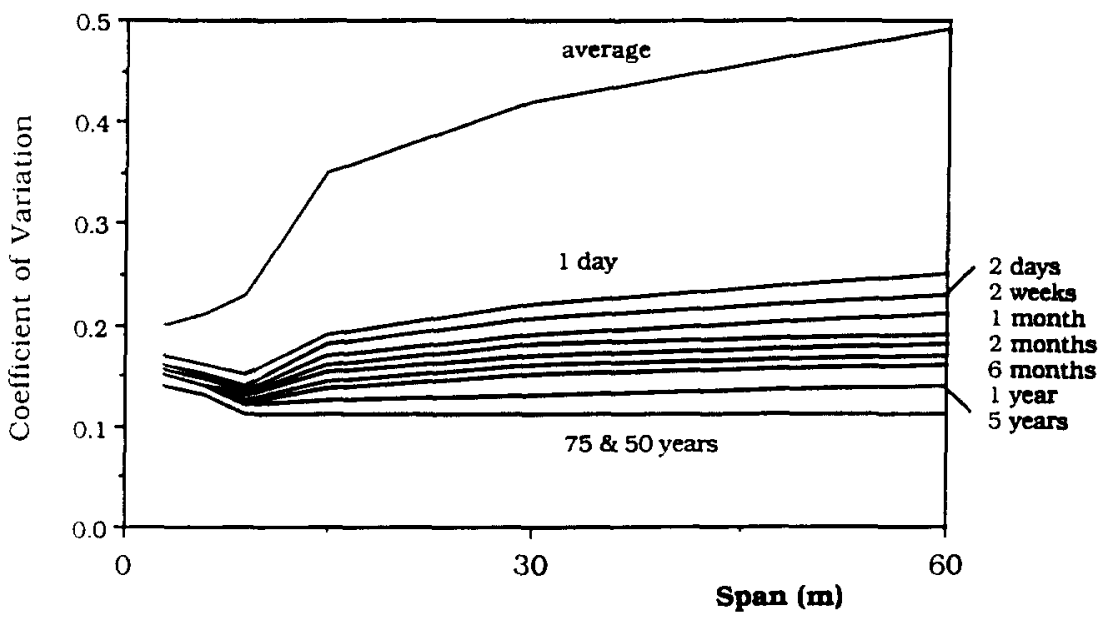

Fig. 8. Coefficient of variation of the maximum moment.

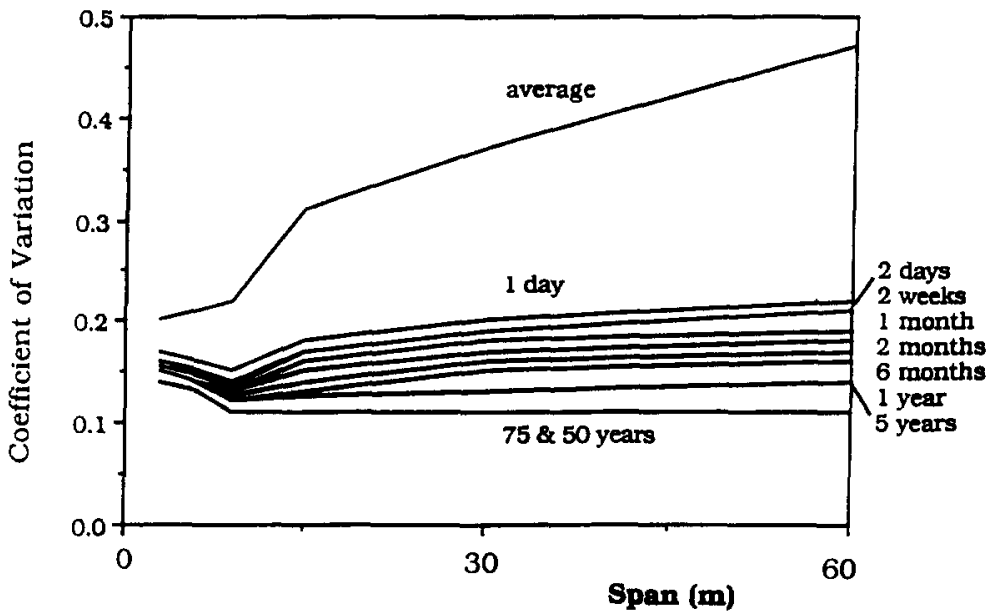

Fig. 9. Coefficient of variation of the maximum shear.

TABLE 3

Truck parameters for two trucks in one lane

\begin{tabular}{|c|c|c|c|c|c|}
\hline \multicolumn{3}{|c|}{ One / two trucks } & \multirow{2}{*}{$\begin{array}{l}N \\
20,000,000\end{array}$} & \multirow{2}{*}{$\begin{array}{l}z \\
5.33\end{array}$} & \multirow{2}{*}{$\frac{T}{75 \text { years }}$} \\
\hline One & & & & & \\
\hline \multirow[t]{6}{*}{ Two: } & $\rho=0$ & Truck 1 & 300,000 & 4.50 & 1 year \\
\hline & & Truck 2 & 1 & 0.00 & average \\
\hline & $\rho=0.5$ & Truck 1 & 150,000 & 4.36 & 6 months \\
\hline & & Truck 2 & 1,000 & 3.09 & 1 day \\
\hline & $\rho=1$ & Truck 1 & 30,000 & 3.99 & 1 month \\
\hline & & Truck 2 & 30,000 & 3.99 & 1 month \\
\hline
\end{tabular}




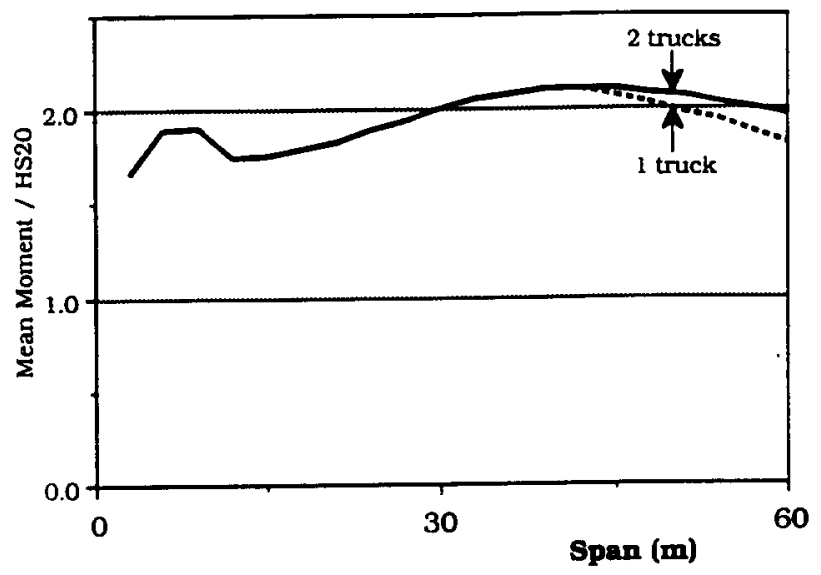

Fig. 10. Mean maximum 75 year simple span moments.

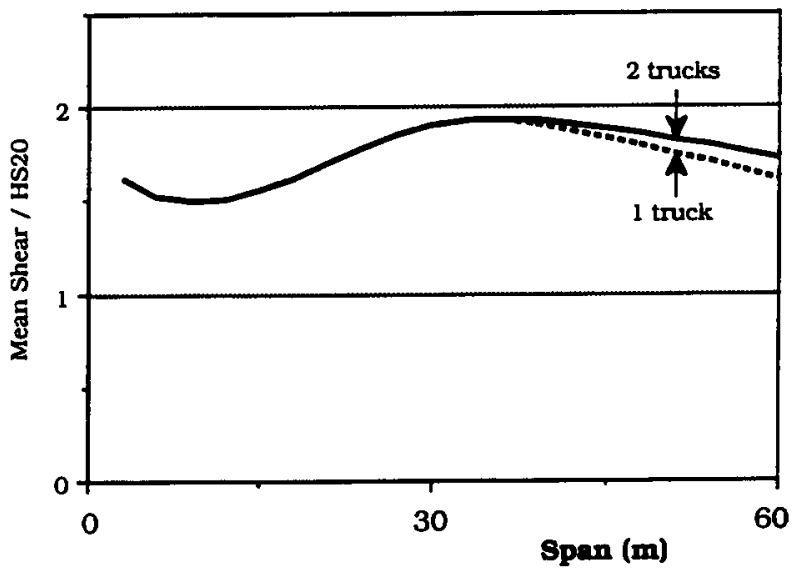

Fig. 11. Mean maximum 75 year shears.

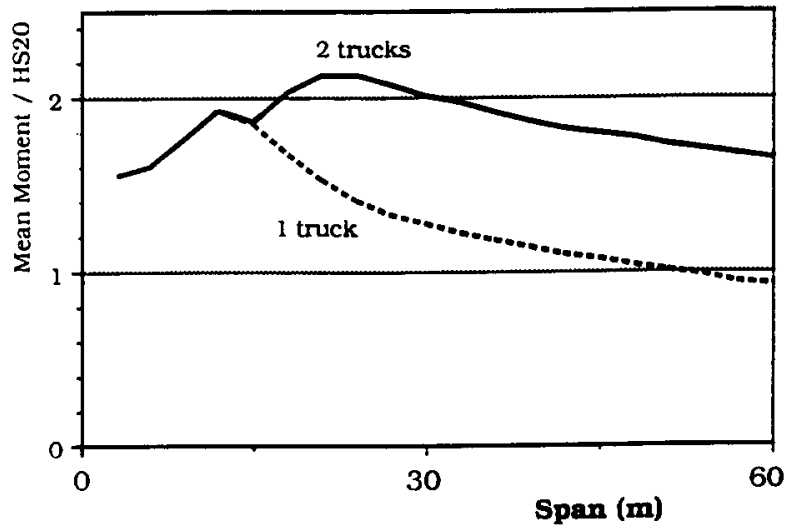

Fig. 12. Mean maximum 75 year negative moments. 


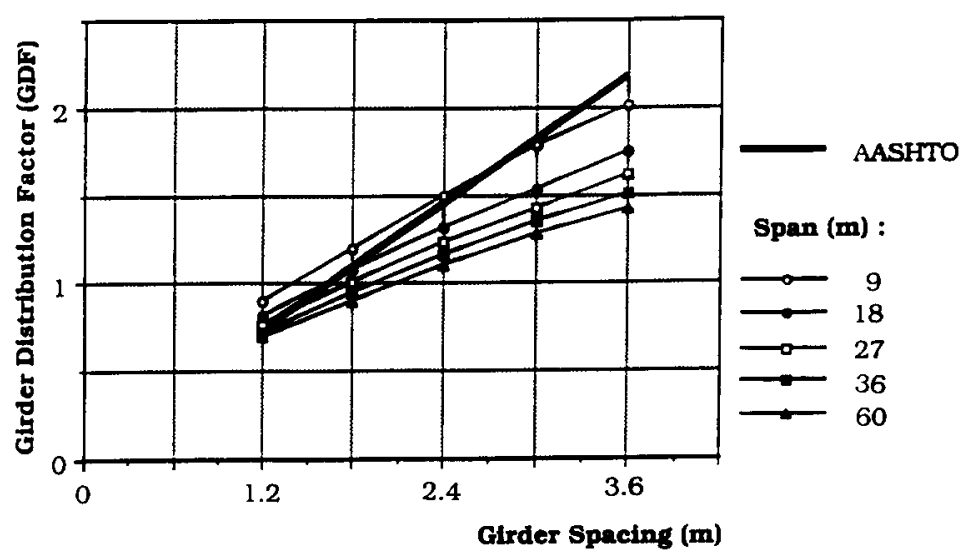

Fig. 13. Girder distribution factors: calculated and specified by AASHTO [1].

For moment in an interior girder, AASHTO [1] specifies a GDF as follows.

$\mathrm{GDF}=s / D$

where $s$ is the girder spacing ( $\mathrm{ft}$; $\mathrm{ft}=0.305 \mathrm{~m}$ ) and $D$ is a constant, equal to 5.5 for steel girders and prestressed concrete girders, and $D=6.0$ for reinforced concrete T-beams. The design moment in a girder is equal to the product of $(0.5 \mathrm{~s} / \mathrm{D})$ and HS20 moment. For shear, AASHTO [1] specifies GDF given by eqn. (2), except of the axle directly over the support. It is assumed that over support the slab is simply supported by the girders.

Zokaie et al. [12] proposed GDF as a function of girder spacing, $s(\mathrm{ft} ; \mathrm{ft}=0.305 \mathrm{~m})$, and span length, $L(\mathrm{ft} ; \mathrm{ft}=0.305 \mathrm{~m})$. For moment in interior girders (steel, prestressed concrete and reinforced concrete T-beams) the formula is

$\mathrm{GDF}=0.15+(s / 3)^{0.6}(s / L)^{0.2}$

and for shear,

$\mathrm{GDF}=0.4+(s / 6)-(s / 25)^{2}$

The results of calculations, performed as a part of this study, are in a good agreement with values obtained using eqn. (3) and (4). However, in most cases, GDF's specified by AASHTO [1] are too conservative. In Fig. 13, calculated GDF's are plotted as a function of girder spacing for spans 9 to $60 \mathrm{~m}$. For comparison, AASHTO [1] GDF's are also shown.

\section{Two lane moments and shears}

The analysis involves the determination of the load in each lane and load distribution to girders. The effect of multiple trucks is calculated by superposition. The maximum effects are calculated as the largest of the following cases:

(1) One lane fully loaded and the other lane unloaded.

(2) Both lanes loaded; three degrees of correlation between the lane loads are considered: no correlation $(\rho=0)$, partial correlation $(\rho=0.5)$ and full correlation $(\rho=1)$. 
TABLE 4

Lane load parameters for two lane traffic

\begin{tabular}{|c|c|c|c|c|c|}
\hline \multicolumn{3}{|c|}{ One/two lanes loaded } & \multirow{2}{*}{$\begin{array}{l}N \\
20,000,000\end{array}$} & \multirow{2}{*}{$\frac{z}{5.33}$} & \multirow{2}{*}{$\begin{array}{l}T \\
75 \text { years }\end{array}$} \\
\hline One & & & & & \\
\hline \multirow{6}{*}{ Two: } & $\rho=0$ & Lane 1 & $1,500,000$ & 4.83 & 5 years \\
\hline & & Lane 2 & 1 & 0.00 & average \\
\hline & $\rho=0.5$ & Lane 1 & 150,000 & 4.36 & 6 months \\
\hline & & Lane 2 & 1,000 & 3.09 & 1 day \\
\hline & $\rho=1$ & Lane 1 & 50,000 & 4.11 & 2 month \\
\hline & & Lane 2 & 50,000 & 4.11 & 2 month \\
\hline
\end{tabular}

It has been observed that, on average, about every 15 th truck is on the bridge simultaneously with another truck (side-by-side). For each such a simultaneous occurrence, it is assumed that every 10 th time the trucks are partially correlated and every 30 th time they are fully correlated (with regard to weight). It is also assumed that the transverse distance between two side-by-side trucks is $1.2 \mathrm{~m}$ (wheel center-to-center).

The parameters of lane load, including $N$ (the considered lane load is the maximum of $N$ occurrences), $z=-\Phi^{-1}(1 / N)$, and $T$ (the considered lane load is the maximum in time period $T$ ) are given in Table 4.

The results of simulations indicate that for interior girders, the case with two fully correlated side-by-side trucks governs, with each truck equal to the maximum 2 month truck. The ratio of a mean maximum 75 year moment and a mean 2 month moment is about 0.85 for all the spans.

\section{Multilane live load for various ADTT}

ADTT (average daily truck traffic) is an important parameter of live load. The observations indicate a considerable site-specific variation of the number of vehicles and percentage of trucks. The live load parameters derived in this paper correspond to ADTT $=1,000$ (truck traffic in all lanes in one direction). The live load moments for multilane bridges with various ADTT's are derived by simulations.

The maximum 75 year moment for a single lane is considered as a reference value. For multiple lanes, moment per lane is lower than that value. For two lanes, the ratio of the per lane moment and the maximum single lane moment is 0.85 (as calculated earlier). For three lanes, the probability of a simultaneous occurrence of very heavy trucks in all three lanes is

TABLE 5

Per lane moment ratios for multilane loads

\begin{tabular}{lllll}
\hline $\begin{array}{l}\text { ADTT } \\
\text { (in one direction) }\end{array}$ & \multicolumn{2}{l}{ Number of lanes } & \\
\cline { 2 - 5 } & 1 & 2 & 3 & 4 \\
\hline 100 & 0.95 & 0.80 & 0.55 & 0.45 \\
1,000 & 1.00 & 0.85 & 0.70 & 0.50 \\
5,000 & 1.05 & 0.90 & 0.75 & 0.55 \\
\hline
\end{tabular}




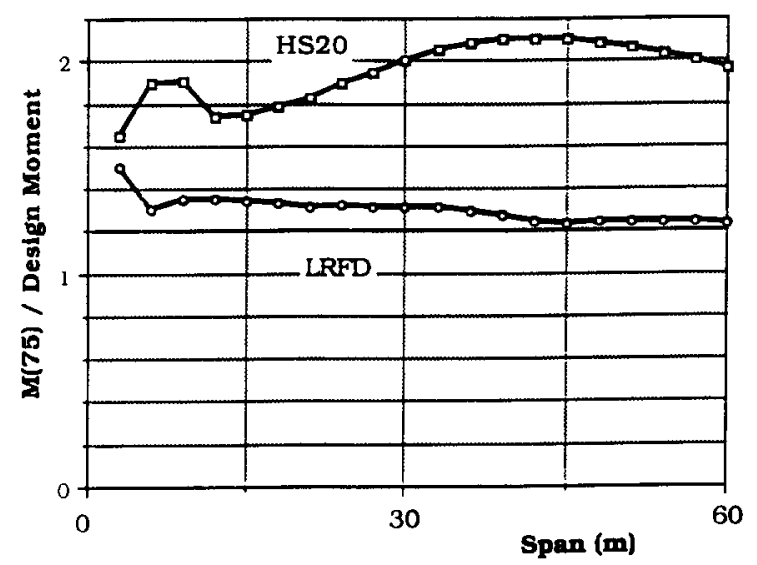

Fig. 14. Bias factors for simple span moments: HS20 and LRFD.

even smaller. Accordingly, the ratio of per lane moment and reference value is 0.70 . For four lanes, the ratio is 0.50 .

For other ADTT's (in one direction), the probabilities of simultaneous occurrence of multiple trucks are different than for ADTT $=1,000$. Therefore, the per lane moments are also different. The moment ratios determined by simulations of multilane traffic are listed in Table 5 .

\section{Design live load}

The objective in the selection of the design live load model is a uniform bias factor. Bias factors calculated for the current AASHTO [1] are plotted in Fig. 10 to 12. To improve the unformity, a new live load is proposed (LRFD AASHTO Code, yet unpublished). LRFD stands for load and resistance factor design. The proposed LRFD load is a superposition of HS20 truck, shown in Fig. 1, and uniform load of $9.35 \mathrm{kN} / \mathrm{m}$. For shorter spans a tandem is specified.

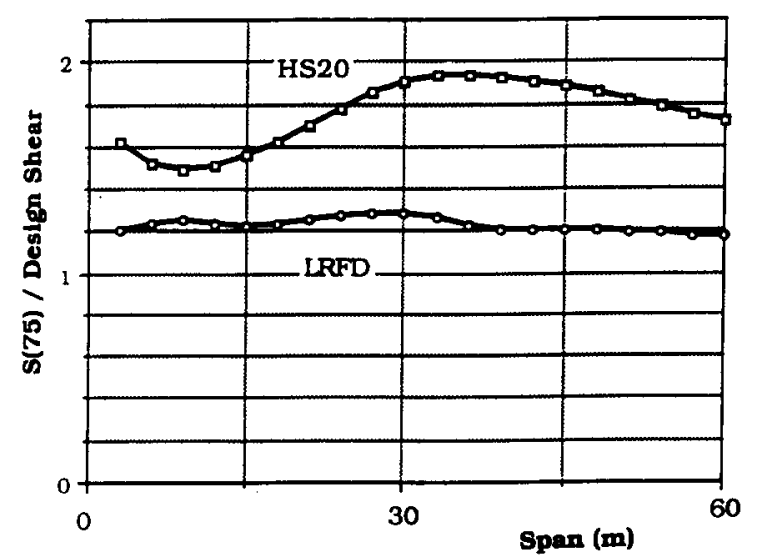

Fig. 15. Bias factors for shears: HS20 and LRFD. 


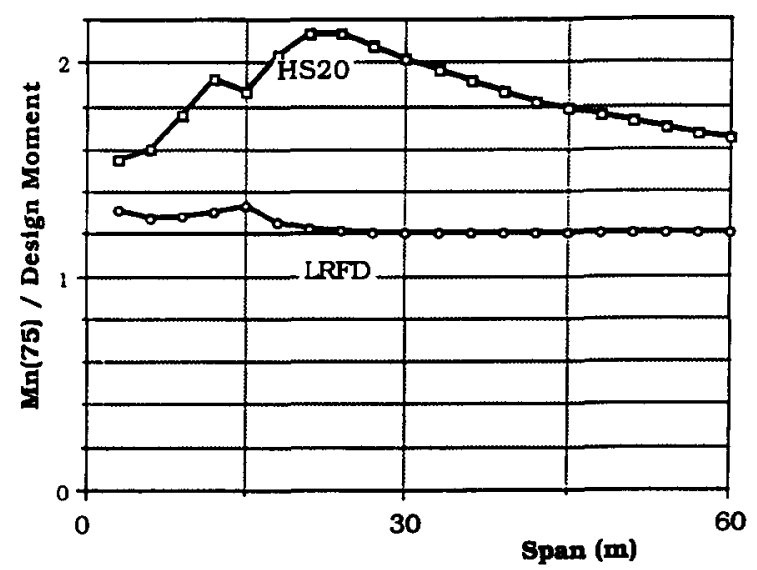

Fig. 16. Bias factors for negative moments: HS20 and LRFD.

For negative moments two HS20 trucks are used, but the total effect is reduced by 10 percent. For comparison, the corresponding bias factors for live load specified by the proposed LRFD and AASHTO [1] are plotted in Fig. 14, 15 and 16 for simple span moment, shear and negative moment, respectively.

The proposed live load model was also used in the development of design loads for the $3 \mathrm{rd}$ edition of OHBDC [2]. The procedures are summarized by Nowak [13].

\section{Conclusions}

The basic load combination for highway bridges is dead load, live load and dynamic load. Statistical models are summarized for dead load and dynamic load. The model is developed for live load. The statistical parameters are derived using the available truck survey data. Moments and shears are calculated for surveyed trucks. The resulting CDF's are extrapolated for longer time periods (up 75 years).

Multiple presence of trucks is calculated in lane and side-by-side. The parameters considered include headway distance and degree of correlation (with regard to weight). The frequency of occurrence is a site-specific parameter. It is modeled on the basis of the available observations. The maximum values are determined by simulations.

It was found that the lane live load moment is governed by a single truck up to about $40 \mathrm{~m}$ span, shear up to about $35 \mathrm{~m}$, and negative moment (continuous spans) up to about $15 \mathrm{~m}$. For two lane bridges, the maximum 75 year effect is caused by two side-by-side maximum two month trucks, with fully correlated weights. The two month truck is about 0.85 of the 75 year truck.

For two lane bridges, girder distribution factor (GDF) is very important. GDF depends on girder spacing and span length. The analysis indicates that the current AASHTO [1] is conservative in most cases, in particular for larger girder spacing.

For multilane bridges, the maximum 75 year effect is caused by a superposition of lane loads. Per lane moments are lower than the maximum 75 year single lane moments. The per lane moment ratios are provided as a function of number of loaded lanes and ADTT. 
The proposed live load model is used in the development of new LRFD codes in the United States and Canada.

\section{Acknowledgments}

The presented research was performed in conjunction with NCHRP Project 12-33 with Co-Principal Investigators, John M. Kulicki and Dennis Mertz. NCHRP was represented by Ian Friedland. The author thanks members of the Calibration Task Group, in particular C. Allin Cornell, Ted. V. Galambos, Dan M. Frangopol and Fred Moses for their discussions and comments. Comments and discussion were also received from the Calibration Committee working on OHBDC, in particular Hid N. Grouni, Roger Dorton, Akhilesh Agarwal and T. Tharmabala.

Thanks are also due to the doctoral students at the University of Michigan, Hani Nassif, Young-Kyun Hong and Eui-Seung Hwang for their help in computations.

\section{References}

[1] AASHTO, Standard specifications for highway bridges, American Association of State Highway and Transportation Officials, Washington, DC, 1989.

[2] OHBDC, Ontario highway bridge design code, Ministry of Transportation, Downsview, Ontario, Canada, 1st Edition 1979, 2nd Edition 1983, 3rd Edition 1991.

[3] A.S. Nowak and N.C. Lind, Practical bridge code calibration, Journal of the Structural Division of ASCE (December 1979) 2497-2510.

[4] H.N. Grouni and A.S. Nowak, Calibration of the Ontario highway bridge design code, The Canadian Journal of Civil Engineering, 11 (4) (December 1984) 760-770.

[5] B. Ellingwood, T.V. Galambos, J.G. MacGregor and C.A. Cornell, Development of a probability based load criterion for American National Standard A58, National Bureau of Standards, NBS Special Publication 577, Washington, DC, 1980.

[6] E-S. Hwang and A.S. Nowak, Simulation of dynamic load for bridges, ASCE Journal of Structural Engineering, 117 (5) (1991) 1413-1434.

[7] M. Ghosn and F. Moses, A Markov renewal model for maximum bridge loading, Journal of Engineering Mechanics, ASCE, 111 (9) (September 1985).

[8] F. Moses et al., Loading spectrum experienced by bridge structures in the United States, Report No. FHWA/RD-85/012, Case Western Reserve University, Cleveland, OH, 1985.

[9] A.S. Nowak and Y-K. Hong, Bridge live load models, ASCE Journal of Structural Engineering, 117 (9) (1991) 2757-2767.

[10] A.C. Agarwal and M. Wolkowicz, Interim report on 1975 commercial vehicle survey, Research and Development Division, Ministry of Transportation, Downsview, Ontario, Canada, 1976.

[11] A.S. Nowak and H. Nassif, Effect of truck loading on bridges, Report UMCE 91-11, Department of Civil Engineering, University of Michigan, Ann Arbor, MI, 1991.

[12] T. Zokaie, T.A. Osterkamp and R.A. Imbsen, Distribution of wheel loads on highway bridges, NCHRP 12-26/1, Proposed changes in AASHTO, Imbsen and Associates, Sacramento, CA, 1992.

[13] A.S. Nowak, Calibration of the OHBDC 1991, Canadian Journal of Civil Engineering, (to appear). 